\title{
Evaluation of antigen detection and polymerase chain reaction for diagnosis of amoebic liver abscess in patients on anti-amoebic treatment
}

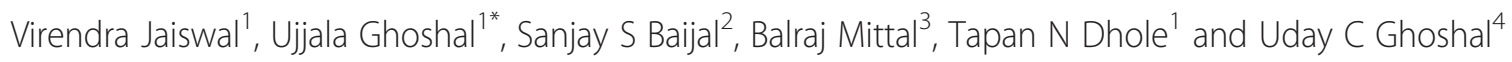

\begin{abstract}
Background: Diagnosis of amoebic liver abscess (ALA) in patients on anti-amoebic drugs is difficult. There is scanty data on this issue using Entamoeba histolytica (E. histolytica) lectin antigen and polymerase chain reaction (PCR). We studied utility of lectin antigen, PCR, and lgG antibody in diagnosis of liver abscess in patients on anti-amoebic treatment. Liver aspirate of 200 patients, of which 170 had anti-amoebic drug prior to drainage, was tested for E. histolytica lectin antigen by (ELISA), PCR, bacterial culture, and serum IgG antibody by (ELISA). Classification of abscesses was based on result of anti-amoebic IgG antibody and bacterial culture, E. histolytica PCR and bacterial culture, and E. histolytica lectin antigen and bacterial culture.
\end{abstract}

Findings: Using anti-amoebic IgG antibody and bacterial culture, 136/200 (68.0\%) were classified as ALA, 12/200 (6.0\%) as pyogenic liver abscess (PLA), 29/200 (14.5\%) as mixed infection, and 23/200 (11.5\%) remained unclassified. Using amoebic PCR and bacterial culture 151/200 (75.5\%) were classified as ALA, 25/200 (12.5\%) as PLA, 16/200 $(8.0 \%)$ as mixed infection, and 8/200 (4.0\%) remained unclassified. With E. histolytica lectin antigen and bacterial culture, 22/200 (11.0\%) patients were classified as ALA, 39/200 (19.5\%) as PLA, 2/200 (1.0\%) as mixed infection, and 137/200 (68.5\%) remained unclassified.

Conclusions: E. histolytica lectin antigen was not suitable for classification of ALA patients who had prior antiamoebic treatment. However, PCR may be used as alternative test to anti-amoebic antibody in diagnosis of ALA.

Keywords: Entamoeba histolytica, Amoebiasis, Pyogenic liver abscess, Anti-amoebic IgG antibody

\section{Findings Introduction}

Amoebic liver abscess (ALA) is caused by protozoan parasite Entamoeba histolytica (E. histolytica), a common parasitic infection in tropical countries [1-3]. Approximately 50 million people are infected with $E$. histolytica annually world-wide, with mortality ranging from 40,000 to $1,000,00$ [4]. Most of the mortality due to amoebiasis results from hepatic rather than intestinal infection. Clinical and radiological features of ALA are often somewhat similar with pyogenic liver abscess (PLA). Hence, necessitating laboratory investigation for differentiation between ALA and PLA are required [5]. Currently ALA is distinguished from PLA by microscopic

\footnotetext{
* Correspondence: ghoshalujjala@yahoo.com

'Department of Microbiology, Sanjay Gandhi Postgraduate Institute of Medical Sciences, Lucknow 226014, India

Full list of author information is available at the end of the article
}

examination, anti-amoebic IgG serology, and culture of aspirate for pyogenic organisms.

Detection of trophozoites on microscopic examination in liver aspirate, though confirmatory of ALA, is quite insensitive [6,7]. Diagnosis of ALA is most frequently made using serum anti-amoebic IgG antibody $[8,9]$. However, this assay may not distinguish past from current infection, especially in endemic regions [10]. Thus, anti-amoebic IgG antibody may also be detected in a proportion of healthy people $[10,11]$.

Sensitivity and specificity of $E$. histolytica lectin antigen have been reported to be as high as $80-90 \%$ in stool and serum specimens for diagnosis of amoebiasis [12$14]$. Detection of $E$. histolytica lectin antigen in liver aspirate may also be useful for diagnosis of liver abscesses. Unfortunately, scanty data available on lectin antigen detection in liver aspirate are often contradictory $[14,15]$. Several PCR types like conventional, nested, touchdown 
and real time have been developed that detect $E$. histolytica DNA in stool samples and liver aspirate $[7,12,16$ 21]. Sensitivity and specificity of conventional PCR is comparable with touchdown as well as real time PCR $[20,22]$. Recently, amoebic DNA has been reported in saliva and urine specimens with low sensitivity $[23,24]$. E. histolytica DNA detection in liver aspirate has been found to be promising for diagnosis of ALA in a few recent studies on a small number of patients $[14,19,25,26]$. Since the administration of antibiotics and anti-amoebic drugs is common in developing countries like India where amoebiasis is endemic, it is essential to evaluate various diagnostic tests in these patients. Accordingly, we aimed to evaluate the anti-amoebic IgG antibody test, E. histolytica lectin antigen assay and conventional PCR in association with bacterial culture for the diagnosis of patients with liver abscess most of whom were on antiamoebic treatment.

\section{Methods}

We examined 220 patients who were subjected to drainage of liver abscesses in the radiology department of a tertiary care center over a 3-yr-period (January 2006 to December 2009). Among 200 patients with well-defined liver abscess, 170 (85.0\%) received an anti-amoebic drug prior to drainage. Liver abscesses were diagnosed by abdominal ultra-sonography. Patients not requiring aspiration, or drainage, or finally diagnosed to have tubercular or fungal abscesses were excluded from the study. Demographic and clinical parameters were recorded in a standard questionnaire. Informed consent was obtained from all the patients and the protocol was approved by the Institution's (Sanjay Gandhi Postgraduate Institute of Medical Sciences, Lucknow-India) Ethics Committee (PGI/DIR/RC/957/2007).

Five $\mathrm{ml}$ of liver aspirate obtained during drainage of abscesses were examined for bacteria using Gram staining and bacterial culture was also done using standard media [27]. Sera obtained from these patients were stored at $-40{ }^{\circ} \mathrm{C}$ till tested. Anti-amoebic IgG antibody was assayed using a commercially available kit (Nova Tec Immunodiagnostica $\mathrm{GmbH}$, CITY, Germany) following the manufacturer's instructions. India is endemic for amoebiasis. Accordingly, 100 age and sex matched volunteers were used as healthy controls for determination of anti-amoebic IgG antibody titer in healthy population. Based on optical density (OD) results from healthy people, a cut-off OD value was determined using receiver operating characteristic (ROC) curve. Serum with an absorbance in excess of cut-off OD on $450 \mathrm{~nm}$ was considered positive. E. histolytica lectin antigen in liver aspirate was identified using commercially available kit (TechLab E. histolytica II, Blacksburg, Virginia) within $24 \mathrm{hr}$ or stored at $-40^{\circ} \mathrm{C}$ for no more than 7 days.
DNA was isolated directly from the liver aspirate samples using CTAB (hexadecyltrimethylammonium bromide) method [28]. A 125 base pair region of extrachromosomal circular DNA of E. histolytica was amplified as previously described [19]. All PCR assays were repeated twice for the validation of the result. DNA extracts from E. histolytica strains HM-1:1MSS were used as positive controls and E. dispar CDC 0784 as a negative control in each PCR run.

Sensitivity, specificity, positive, and negative predictive values (PPV, NPV) were calculated using standard formulae [29]. Continuous and qualitative variables were analyzed using independent sample $t$-test, Pearson's Chisquare, and Fisher's exact test wherever appropriate. Two-tailed $P$-values $<0.05$ were considered as significant.

\section{Results}

Twenty patients were excluded from the final analysis as a definite diagnosis could not be made due to inadequate work-up ( $n=12)$, or drainage not needed $(n=4)$, tubercular liver abscesses $(n=2)$, and fungal liver abscesses $(n=2)$. Demographic, clinical, imaging and laboratory data of 200 patients with liver abscess are shown in Additional file 1: Table S1. Patients with ALA were younger in age, more often male, and had history of alcoholism, diarrhea in the recent past, or blood in the stool (dysenteric). In contrast, patients with PLA were more often diabetic, and had gall stones. On laboratory investigation, patients with PLA had lower levels of serum albumin, alanine aminotransferase (ALT), aspartate aminotransferase (AST), and higher hemoglobin than those with ALA. A solitary lesion in right lobe of liver was seen more frequently in ALA than PLA on imaging.

Bacteria were found in 41 of 200 (20.5\%) liver aspirate samples on microscopic examination of the Gram stained smears and cultures. In 28 of 41 (68.3\%) patients, there was a single species of bacteria in their aspirate. However, 13 of 41 (31.7\%) patients had mixed infection of bacteria in their aspirate. These included Escherichia coli $(\mathrm{n}=19)$, Klebsiella pneumoniae $(\mathrm{n}=12)$, Pseudomonas aeruginosa $(\mathrm{n}=6)$, Staphylococcus sp. $(\mathrm{n}=4)$, Acinetobacter baumannii $(\mathrm{n}=4)$, Enetrobacter sp. $(\mathrm{n}=4)$, Proteus vulgaris $(\mathrm{n}=2)$, Morganella sp. $(\mathrm{n}=1)$.

Based on the OD from healthy controls, a cut-off OD value was designated. Best sensitivity (83\%) and specificity $(63 \%)$ of a commercially available kit was calculated using ROC curve at $\mathrm{OD}=0.291$. In total, 165 of 200 (82.5\%) liver abscess patients produced an OD >0.291. However, 35 of 200 (17.5\%) patients with liver abscesses had an $\mathrm{OD}<0.291$, while 141 of 170 (82.9\%) patients had anti-amoebic IgG antibody in their sera, which were collected after initiation of the anti-amoebic drug. In contrast, 24 of $30(80.0 \%)$ patients had anti-amoebic IgG 
antibody in their sera, which were collected before initiation of the anti-amoebic drug $(P=\mathrm{ns})$.

$E$. histolytica lectin antigen was present in $24 / 200$ (12\%) liver aspirate. Detection of lectin antigen in liver aspirate was significantly lower in patients who had received prior anti-amoebic treatment $(4 / 170,2.4 \%$ vs 20/30, 66.7\%, P<0.001).

Amoebic DNA was detected in 167/200 (83.5\%) patients. E. histolytica DNA was amplified more commonly in patients who had received prior anti-amoebic drugs $(144 / 170,84.7 \%$ vs $23 / 30,76.7 \%, P>0.05)$.

\section{Classification of liver abscesses using anti-amoebic lgG antibody and bacterial culture}

In 136 of 200 (68\%) patients with liver abscess classified as ALA as anti-amoebic IgG antibody was present in their sera, and aspirate was sterile on bacterial culture. Twelve of 200 (6.0\%) patients were classified as pyogenic as their sera did not show anti-amoebic IgG antibody, while their aspirate culture revealed growth of a pyogenic organism. Twenty-nine of 200 (14.5\%) were classified as mixed infection since their sera had anti-amoebic IgG antibody and aspirate culture revealed presence of bacteria; 23 of 200 (11.5\%), however, remained unclassified as their sera did not have anti-amoebic IgG antibody and aspirate was also sterile on bacterial culture (Table 1).

\section{Classification of liver abscesses using E. histolytica PCR and bacterial culture}

In 151 of $200(75.5 \%)$ patients with liver abscess were classified as ALA as their aspirate had E. histolytica DNA and bacterial culture was sterile. Twenty-five of $200(12.5 \%)$ were classified as pyogenic, since their aspirate did not show $E$. histolytica DNA but grew bacteria on culture. Sixteen of 200 (8.0\%) patients were classified as having a mixed infection as their aspirate had both E. histolytica DNA and bacteria grew on culture, while 8 of $200(4.0 \%)$ remained unclassified as their aspirate did not have E. histolytica DNA and bacterial culture was sterile (Table 1).

\section{Classification of liver abscesses using E. histolytica lectin antigen and bacterial culture}

Twenty-two of 200 (11.0\%) patients with liver abscess were classified as amoebic since their aspirate had
E. histolytica lectin antigen, but was sterile on bacterial culture. Thirty-nine of 200 (19.5\%) were classified as pyogenic as their aspirate did not show E. histolytica lectin antigen, but bacteria grew on culture, and 2 of 200 (1.0\%) were classified as mixed infections as their aspirate was positive both for E. histolytica lectin antigen and bacterial culture. However, 137 of 200 (68.5\%) remained undiagnosed as their aspirate was negative for both E. histolytica lectin antigen and bacterial culture (Table 1).

Using a combination of various tests, patients not classified into any category was highest by $E$. histolytica lectin antigen and bacterial culture and lowest using E. histolytica PCR and bacterial culture $[8 / 200$ (4.0\%), $23 / 200$ (11.5\%), and $137 / 200$ (68.5\%) $P=0.000]$. The number of patients classified as ALA was highest using E. histolytica $\mathrm{PCR}$ and bacterial culture, compared to anti-amoebic IgG antibody and $E$. histolytica lectin with bacterial culture [151/200 (75.5\%), 136/200 (68.0\%), and 22/200 (11\%) $P=0.000$ ] (Table 1).

\section{Sensitivity and specificity}

Patients with mixed and unclassified infections were excluded for the calculation of sensitivity, specificity, PPV, and NPV. Considering anti-amoebic IgG antibody and bacterial culture as gold standards, sensitivity, specificity, PPV, and NPV of E. histolytica PCR and E. histolytica lectin antigen ELISA were 99\%, 91\%, 99\%, 91\% and $15 \%, 100 \%, 100 \%, 9.3 \%$, respectively. Using $E$. histolytica PCR and bacterial culture as gold standard, sensitivity, specificity, PPV, and NPV of anti-amoebic IgG antibody and E. histolytica lectin antigen ELISA were $89 \%, 56 \%$, $90 \%, 44 \%$ and $14.5 \%, 100 \%, 100 \%, 17 \%$, respectively. The measurement of agreement between anti-amoebic IgG antibody and E. histolytica lectin antigen was low [kappa value $(\mathrm{k})=0.002]$ and association between these 2 tests were also not significant $(P=0.911)$. However, antiamoebic IgG antibody and E. histolytica PCR had agreement $(\mathrm{k}=0.456)$ and the 2 tests were significant $(P<0.001$, Table 2$)$.

\section{Discussion}

The current study showed that E. histolytica lectin antigen in association with bacterial culture of liver aspirate was less useful in classifying liver abscesses. In contrast, serum anti-amoebic IgG antibody or E. histolytica PCR in combination with bacterial culture classified most of

Table 1 Classification of patients with liver abscess using various such as tests anti-amoebic IgG antibody, E. histolytica PCR, E. histolytica lectin antigen and bacterial culture $(n=200)$

\begin{tabular}{|c|c|c|c|c|}
\hline & Amoebic liver abscess & Pygenic liver abscess & Mixed Infection & Unclassified \\
\hline IgG Ab + Bacterial Culture & $136,(68 \%)$ & $12,(6 \%)$ & $29,(14.5 \%)$ & $23,(11.5 \%)$ \\
\hline Amoebic DNA + Bacterial Culture & $151,(75.5 \%)$ & $25,(12.5 \%)$ & $16,(8 \%)$ & $8,(4 \%)$ \\
\hline Lectin Antigen + Bacterial Culture & $22,(11 \%)$ & $39,(19.5 \%)$ & $2,(1 \%)$ & $137,(68.5 \%)$ \\
\hline
\end{tabular}


Table 2 Agreement between anti-amoebic IgG antibody with E. histolytica-lectin antigen and E. histolytica-PCR among $A L A *$ and unclassified patients $(n=159)$

\begin{tabular}{|c|c|c|c|c|c|c|}
\hline & & \multicolumn{2}{|c|}{ Disease status by lgG } & \multirow[t]{2}{*}{ Total } & \multirow[t]{2}{*}{ Kappa value } & \multirow[t]{2}{*}{$P$ value } \\
\hline & & ALA & Unclassified & & & \\
\hline \multirow{2}{*}{$\begin{array}{l}\text { Disease status by } \\
\text { E. histolytica Ag }\end{array}$} & ALA & 20 & 2 & 22 & 0.020 & 0.447 \\
\hline & Unclassified & 116 & 21 & 137 & & \\
\hline Total & & 136 & 23 & 159 & & \\
\hline Disease status & ALA & 135 & 15 & 150 & 0.456 & 0.001 \\
\hline by PCR & Unclassified & 1 & 8 & 9 & & \\
\hline Total & & 136 & 23 & 159 & & \\
\hline
\end{tabular}

*Amoebic liver abscess

the liver abscesses and confirmed the biological significance of these conditions to a reasonable degree [3].

Our study showed that TechLab E. histolytica lectin antigen test was not useful for diagnosis of ALA. This is in contrast to 2 previously reported results in which sensitivity of this test in liver aspirate sample were $40.7 \%$ and 50.0\%, respectively [14,15]. Anti-amoebic drugs are known to cause false negative results using E. histolytica lectin antigen assay in an animal model [30]. In a study published recently from Malaysia, 29 of 32 (90.6\%) patients with ALA [31], E. histolytica lectin antigen had become negative in sera within $48 \mathrm{hr}$ of metronidazole administration. Another study showed, 3 of $7(42.9 \%)$ patients were positive for E. histolytica lectin antigen prior to treatment while only $3 / 40(7.5 \%)$ patients had lectin antigen during or after treatment [14]. The same study also reported that 9/11 (81.8\%) serum samples of patients with ALA had become negative for E. histolytica lectin antigen after $1 \mathrm{wk}$ of antiamoebic treatment. In developing countries where amoebiasis is endemic, anti-amoebic drugs are often used indiscriminately. This could explain the low sensitivity of E. histolytica lectin antigen test on liver aspirate in our study. Thus, E. histolytica lectin antigen test is not useful for diagnosis of ALA in patients receiving anti-amoebic treatment.

One sample was negative by PCR but positive by IgG antibody. The possible explanation to this could be presence of PCR inhibitors in liver aspirate as present in stool samples. Although, we used inhibitors tablet to optimize the PCR, some PCR inhibitors might be coextracted with the DNA, which inhibited the PCR.

One interesting finding of the present study is 2 patients with of ALA, which were diagnosed by PCR but not by IgG antibody. Presence of amoebic DNA in two liver aspirates specimens, establishes amoebic infection in them. The negative result of ELISA (IgG) shows that the host made an alternate mechanism for defense against the parasite. The above cases present an interesting area of research on defense mechanism in host infected with E. histolytica.
In the present study we have used conventional PCR for diagnosis of ALA. Using E. histolytica PCR with bacterial culture, most of patients with liver abscess were classified as ALA. E. histolytica PCR had greater sensitivity for diagnosis of ALA than anti-amoebic IgG antibody. Twenty-three patients with liver abscess in the present study could not be unclassified using antiamoebic antibody with bacterial culture. However, only 8 patients were remained unclassified by $E$. histolytica PCR with bacterial culture. Thus in country like India where real time PCR is not available in all laboratories, conventional PCR can be used for the diagnosis of ALA. It reduces cost of sample processing compared to in real time and nested PCR.

\section{Conclusions}

E. histolytica lectin antigen in combination with bacterial culture was least useful in classifying liver abscesses in patients who had received anti-amoebic drug prior to collection of the liver aspirate sample; in contrast, a combination of serum anti-amoebic antibody or E. histolytica PCR and bacterial culture classified most of the liver abscesses successfully.

\section{Additional file}

Additional file 1: Table S1. Demographic and clinical features of 200 liver abscess patients classify using anti-amoebic lgG antibody and bacterial culture.

\section{Abbreviations}

ALA: Amoebic liver abscess; PLA: Pyogenic liver abscess; PCR: Polymerase chain reaction; E. histolytica: Entamoeba histolytica; ALT: Alanine aminotransferase; AST: Aspartate aminotransferase; OD: Optical density; ROC: Receiver operating characteristics.

\section{Competing interests}

The authors declare that they have no financial and non financial competing interests.

\section{Authors' contribution}

UG-Additional Professor and UCG-Additional Professor conceived the study; BM-Professor and TND-Professor designed the protocol; SSB-Professor drained liver pus from patients; VJ-PhD student carried out microscopy, ELISA, PCR; VJ, UG and UCG analysed the data and drafted manuscript; UCG 
performed the statistical analysis; all authors read and approved the final version. UG is guarantor of the paper.

\section{Acknowledgments}

The authors wish to express many thanks to Dr. C. G. Clark (Department of Infectious and Tropical diseases, London School of Hygiene and Tropical Medicine, London, U.K.) and Prof. S. Bhattacharya (School of Environmental sciences, Jawahar Lal Nehru University, New Delhi, India), for providing DNA of E. histolytica and E. dispar for validation of the results.

\section{Author details}

'Department of Microbiology, Sanjay Gandhi Postgraduate Institute of Medical Sciences, Lucknow 226014, India. ${ }^{2}$ Department of Radiology, Sanjay Gandhi Postgraduate Institute of Medical Sciences, Lucknow 226014, India. ${ }^{3}$ Department of Genetics, Sanjay Gandhi Postgraduate Institute of Medical Sciences, Lucknow 226014, India. ${ }^{4}$ Department of Gastroenterology, Sanjay Gandhi Postgraduate Institute of Medical Sciences, Lucknow 226014, India.

Received: 3 May 2012 Accepted: 16 July 2012

Published: 7 August 2012

\section{References}

1. Ahsan T, Jehangir MU, Mahmood T, Ahmed N, Saleem M, Shahid M, Shaheer A, Anwer A: Amoebic versus pyogenic liver abscess. J Pak Med Assoc 2002, 52:497-501.

2. Kaplan GG, Heitman SJ, Hilsden RJ, Urbanski S, Myers RP, Lee SS, Burak KW, Swain M, Panaccione R: Population-based analysis of practices and costs of surveillance for colonic dysplasia in patients with primary sclerosing cholangitis and colitis. Inflamm Bowel Dis 2007, 13:1401-1407.

3. Lodhi S, Sarwari AR, Muzammil M, Salam A, Smego RA: Features distinguishing amoebic from pyogenic liver abscess: a review of 577 adult cases. Trop Med Int Health 2004, 9:718-723.

4. World Health Organization: Amoebiasis. Wkly Epidemiol Rec 1997, 72:97-100.

5. Sheen IS, Chien CS, Lin DY, Liaw YF: Resolution of liver abscesses: comparison of pyogenic and amebic liver abscesses. Am J Trop Med Hyg 1989, 40:384-389.

6. Fotedar R, Stark D, Beebe N, Marriott D, Ellis J, Harkness J: PCR detection of Entamoeba histolytica, Entamoeba dispar, and Entamoeba moshkovskii in stool samples from Sydney, Australia. J Clin Microbiol 2007, 45:1035-1037.

7. Haque R, Faruque AS, Hahn P, Lyerly DM, Petri WA Jr: Entamoeba histolytica and Entamoeba dispar infection in children in Bangladesh. J Infect Dis 1997, 175:734-736.

8. Zengzhu G, Bracha R, Nuchamowitz Y, Cheng IW, Mirelman D: Analysis by enzyme-linked immunosorbent assay and PCR of human liver abscess aspirates from patients in China for Entamoeba histolytica. J Clin Microbiol 1999, 37:3034-3036.

9. Ravdin Jl, Jackson TF, Petri WA Jr, Murphy CF, Ungar BL, Gathiram V, Skilogiannis J, Simjee AE: Association of serum antibodies to adherence lectin with invasive amebiasis and asymptomatic infection with pathogenic Entamoeba histolytica. J Infect Dis 1990, 162:768-772.

10. Caballero-Salcedo A, Viveros-Rogel M, Salvatierra B, Tapia-Conyer R, Sepulveda-Amor J, Gutierrez G, Ortiz-Ortiz L: Seroepidemiology of amebiasis in Mexico. Am J Trop Med Hyg 1994, 50:412-419.

11. Sanchez-Guillen MC, Merino-Guzman G, Perez-Fuentes R, Rosales-Encina JL, Talamas-Rohana P: Serologic characterization of Entamoeba histolytica asymptomatic carriers from a community of Puebla state, Mexico. Arch Med Res 1997, 28:322-324.

12. Haque R, Ali IK, Akther S, Petri WA Jr: Comparison of PCR, isoenzyme analysis, and antigen detection for diagnosis of Entamoeba histolytica infection. J Clin Microbiol 1998, 36:449-452.

13. Haque R, Neville LM, Hahn P, Petri WA Jr: Rapid diagnosis of Entamoeba infection by using Entamoeba and Entamoeba histolytica stool antigen detection kits. J Clin Microbiol 1995, 33:2558-2561.

14. Haque R, Mollah NU, Ali IK, Alam K, Eubanks A, Lyerly D, Petri WA Jr: Diagnosis of amebic liver abscess and intestinal infection with the TechLab Entamoeba histolytica II antigen detection and antibody tests. J Clin Microbiol 2000, 38:3235-3239.

15. Parija SC, Khairnar K: Detection of excretory Entamoeba histolytica DNA in the urine, and detection of E. histolytica DNA and lectin antigen in the liver abscess pus for the diagnosis of amoebic liver abscess. BMC Microbiol 2007, 7:41.

16. Britten D, Wilson SM, McNerney R, Moody AH, Chiodini PL, Ackers JP: An improved colorimetric PCR-based method for detection and differentiation of Entamoeba histolytica and Entamoeba dispar in feces. J Clin Microbiol 1997, 35:1108-1111.

17. Tannich E, Burchard GD: Differentiation of pathogenic from nonpathogenic Entamoeba histolytica by restriction fragment analysis of a single gene amplified in vitro. J Clin Microbiol 1991, 29:250-255.

18. Troll H, Marti H, Weiss N: Simple differential detection of Entamoeba histolytica and Entamoeba dispar in fresh stool specimens by sodium acetate-acetic acid-formalin concentration and PCR. J Clin Microbiol 1997, 35:1701-1705.

19. Zaman S, Khoo J, Ng SW, Ahmed R, Khan MA, Hussain R, Zaman V: Direct amplification of Entamoeba histolytica DNA from amoebic liver abscess pus using polymerase chain reaction. Parasitol Res 2000, 86:724-728.

20. Roy S, Kabir M, Mondal D, Ali IK, Petri WA Jr, Haque R: Real-time-PCR assay for diagnosis of Entamoeba histolytica infection. J Clin Microbiol 2005, 43:2168-2172.

21. Othman N, Mohamed Z, Verweij JJ, Huat LB, Olivos-Garcia A, Yeng C, Noordin R: Application of real-time polymerase chain reaction in detection of Entamoeba histolytica in pus aspirates of liver abscess patients. Foodborne Pathog Dis 2010, 7:637-641.

22. Singh P, Mirdha BR, Ahuja V, Singh S: Evaluation of small-subunit rRNA touchdown polymerase chain reaction for direct detection of Entamoeba histolytica in human pus samples from patients with amoebic liver abscess. Indian J Med Microbiol 2011, 29:141-146.

23. Haque R, Kabir M, Noor Z, Rahman SM, Mondal D, Alam F, Rahman I, Al Mahmood A, Ahmed N, Petri WA Jr: Diagnosis of amebic liver abscess and amebic colitis by detection of Entamoeba histolytica DNA in blood, urine, and saliva by a real-time PCR assay. J Clin Microbiol 2010, 48:2798-2801.

24. Khairnar K, Parija SC: Detection of Entamoeba histolytica DNA in the saliva of amoebic liver abscess patients who received prior treatment with metronidazole. J Health Popul Nutr 2008, 26:418-425.

25. Zindrou S, Orozco E, Linder E, Tellez A, Bjorkman A: Specific detection of Entamoeba histolytica DNA by hemolysin gene targeted PCR. Acta Trop 2001, 78:117-125.

26. Khan U, Mirdha BR, Samantaray JC, Sharma MP: Detection of Entamoeba histolytica using polymerase chain reaction in pus samples from amebic liver abscess. Indian J Gastroenterol 2006, 25:55-57.

27. Collee JG, Fraser AG: Marmion BP. Simmons A: Mackie \& McCartney practical medical microbiology; 1999.

28. Clark CG DL: The Laredo strain and other Entamoeba histolytica-like amoebae are Entamoeba moshkovskii. Mol Bio chem Parasitol 1991, 46:11-18.

29. Bewick V, Cheek L, Ball J: Statistics review 13: receiver operating characteristic curves. Crit Care 2004, 8:508-512.

30. Thammapalerd N, Sherchand JB, Kotimanusvanij D, Chintana T, Tharavanij S: Monoclonal antibody-based ELISA for the detection of circulating Entamoeba histolytica antigen in hepatic amebiasis in hamsters (Mesocricetus auratus). Southeast Asian J Trop Med Public Health 1996, 27:760-764.

31. Zeehaida M, Wan Nor Amilah WA, Amry AR, Hassan S, Sarimah A, Rahmah $\mathrm{N}$ : A study on the usefulness of Techlab Entamoeba histolytica II antigen detection ELISA in the diagnosis of amoebic liver abscess (ALA) at Hospital Universiti Sains Malaysia (HUSM), Kelantan, Malaysia. Trop Biomed 2008, 25:209-216.

\section{doi:10.1186/1756-0500-5-416}

Cite this article as: Jaiswal et al: Evaluation of antigen detection and polymerase chain reaction for diagnosis of amoebic liver abscess in patients on anti-amoebic treatment. BMC Research Notes 2012 5:416. 